\title{
Technological research plan for active ageing
}

\author{
Hamideh Afsarmanesh • Simon Samwel Msanjila • \\ Luis M. Camarinha-Matos
}

Published online: 18 February 2011

(C) The Author(s) 2011. This article is published with open access at Springerlink.com.

\begin{abstract}
The ePAL initiative aimed at developing a roadmap for extension of professional active life of the retiring and retired knowledge workers in developed countries and specifically in Europe. Three main perspectives are identified in this roadmap, and defined to comprehensively address relevant dimensions of the ePAL environment. These three perspectives consist of: (1) the technological perspective that addresses the needed technology and the support services, (2) the societal perspective that addresses both the human factors and the societal aspects, and (3) the organizational perspective that addresses both the economic / managerial and governmental aspects of these environments. This document however aims to zoom in on the technological perspective of the roadmap. Following a brief description of the three main perspectives of the ePAL environment, it introduces the four main ICT research and development areas that are identified for strengthening and realization of active ageing. The technological perspective of the ePAL's vision constitutes a substantial part of the roadmap recommendations.
\end{abstract}

H. Afsarmanesh $(\triangle)$

Informatics Institute / Computer Science Department,

University of Amsterdam,

Science Park 904,

1098 XH Amsterdam, The Netherlands

e-mail: h.afsarmanesh@uva.nl

URL: http://www.science.uva.nl/ hamideh

\section{S. S. Msanjila}

Department of Information and Communication Technologies,

Mzumbe University,

Mzumbe, Tanzania

e-mail: simon.msanjila@gmail.com

L. M. Camarinha-Matos

Department of Electrical Engineering, New University of Lisbon,

Lisbon, Portugal

e-mail: cam@uninova.pt
This article further addresses the state of the art in each of these four areas and exemplifies their application needs in the ePAL environment.

Keywords Active ageing . Technological perspective . Collaborative networks $\cdot$ Roadmap

\section{Introduction}

A critical challenge facing the societies in developed countries is how to support the "active ageing / ageing well" process (Afsarmanesh et al. 2009) for its knowledge workers in the coming decades. It is required to identify new societal positions, governmental policies, and organizational structures, together with the needed technology and support systems and tools to improve the existing and emerging situations (Leonard et al. 2009). It is desired that the retired/retiring elderly citizens have the possibility of remaining partially involved in the market/society, and thus have the opportunity to use their knowledge and expertise in making valued contributions to the communities where they live (Jettinghoff and Houtman 2007). Another angle to this challenge is the fact that in respect to retirees and senior citizens, different regions of the world are not homogeneous. Namely, even if considering Europe, in some countries, mostly located in north and central Europe, retirement represents the period of relaxation and leisure, while in some other European countries, mostly located in East Europe, it represents the period of desperately looking for second jobs and worrying about many financial consequences of retirement (Carey 2009).

Current forecasts show a sharp increase in size of the older population of Europe in the coming decades, while the growth in the middle-aged population is slowing down in this period. People tend to have a longer and healthy life 
(Carey 2009). Thus, seniors are becoming an increasingly important labor source throughout Europe. Furthermore, it is being gradually noticed by some industries that seniors can typically bring maturity, dependability, and years of relevant experience to the workplace, which is in contrast with more traditional practices of replacing older workers by younger ones (IPWEA 2006). Consequently, it is foreseen that in near future retirement for knowledge workers might no longer represent the end of the working period, rather a lifestyle and career transition, where the retirees in principle have multiple options. In this direction our study of the baseline within the ePAL roadmapping initiative has revealed a number of such options: continuing to work (though perhaps at a different pace), returning to school for additional training or education, changing career, venturing into entrepreneurship, becoming more involved in volunteer work, and simply enjoying leisure and travel possibilities (Camarinha-Matos and Afsarmanesh 2009). Thus a mix of working, learning, relaxing, and trying new things is being gradually foreseen as possibilities (Avramov and Maskova 2003), (HSBC Insurance 2007).

Currently, most initiatives supporting seniors are focused on their socialization and entertainment activities, while new organizational forms and mechanisms are emerging, which are focused on providing ways to help senior professionals remain partially active after their retirement (del Cura et al. 2009), (Afsarmanesh and Msanjila 2010). However, the ePAL (extending Professional Active Life) project, fundded by the European Commission, which partially constitutes the base for research results reported in this paper, aims at a comprehensive address of this problem area. The ePAL project develops a European vision and roadmap for extending professional active life, indicating a set of recomended actions to support the society with achieving the ePAL's vision, and helping senior professionals with having an enjoyable active life, balanced between work and leisure. As such the ePAL approach complements some other initiatives that target supporting the active ageing workers with learning to use new tools necessary for continuing their work, e.g. the eSangathan project (Turbe-Suetens and Kouloumdjian 2009). These initiatives investigate the use of ICT, the collaborative working environments, and the Web 2.0 tools by senior professionals, and the role that can be played by training seniors for this endeavor.

Furthermore, a few other recent initiatives are being established in some countries by various actors from government to industry, in order to address the problem of ageing labor forces and enhancing the quality of life of the retired professionals (Age Platform Europe: http://www. age-platform.eu/en). Their principal aims include: attracting senior professionals and joining their efforts in some sort of collaborative networks, brokering work opportuni- ties for willing retirees, establishing intermediaries between retirees and business sector, establishing policies and regulations in favor of senior professionals, building ICT infrastructure and application functionalities for seniors with emphasis on user friendly interfaces, etc. Other examples can also be found in the other continents, e.g. Australia (IPWEA 2006) and the USA (Walker 2007), (Eyster at al. 2008).

Most R\&D efforts in this area, both past and present, have adopted a reactive strategy while trying to mitigate the problems "after" the elderly reach a critical phase in dependency. ePAL however adopts a proactive strategy, identifying measures of a more "preventive" nature, towards facilitating active ageing / ageing well. In the remaing of this article, Section 2 presents the adopted roadmapping perspectives and strategy. Section 3 briefly introduces the roadmapping framework. Section 4 provides a summary of the three perspectives addressed by the ePAL roadmap. Sections 5, 6, 7 and 8 respectively address the four ICT areas of: Collaborative Networks, Affective Computing, Soft Computing, and Machine Learning, which are the main technological contributors to the ePAL environment and therefore in need of strong research and development activities. Section 9 classifies the addressed cahllenges in each of the four ICT areas, and summarizes for each class both the research results so far achieved, as well as the research which is still required to be performed. Section 10 concludes this article.

\section{2 ePAL roadmapping perspectives and strategy}

Within the ePAL roadmap three orthogonal perspectives are defined, called the technological, societal, and organizational perspectives. These three perspectives are identified through a rigorous visioning exercise as expalined in (Afsarmanesh et al. 2009). These perspectives comprehensively address the problem area and identify ePAL's future vision, as well as identifying the activities required to reach that vision.

For the societal and organizational perspectives there is a chronic shortage of good practicing models which can effectively leverage the usage of the skills of seniors (Leonard et al. 2009). Both regulated societal support for senior professionals as well as governmental regulations are lacking. There is also still a lack of communication between employers/customers and seniors concerning the skills and experience they can effectively bring to the marketplace. While some positive examples illustrate how SMEs and start-ups can benefit from support offered by seniors, the demand has remained quite residual. Effective new brokers and societal/ governmental support are needed to ensure that such issues do not slow down the rate of senior 
involvement and adaptation of recruitment and employment practices to the new demographic realities of the EU.

In the technological sector, the main focus of this document, it is clear that many of the current advances in ICT are not aimed at Senior Professionals as a target user (Hernandez-Encuentra, et al. 2009). This is perhaps because those that design the software by large do not come from a senior generation themselves, and have no proper understanding of the needs of seniors, to consider them as input to their design. This however leads to a vicious cycle, whereby software and their applications are designed for a younger user who then becomes its chief consumer and market, influencing its future development (Lundberg 2007). Even if this cycle cannot be easily broken, the new trend on adaptable interfaces can help seniors overcome this lack, through allowing them to adapt ICT tools to their needs.

The above tendency is no less evident in social networks which are the popular phenomena amongst younger generations, who connect with them in vast numbers, and are designed and built around applications with this sector of the society very much in mind. Facebook, Bebo and MySpace for instance have made ICT a very important force in mobilizing the social capital of a younger generation, who both relate to this field of communication and are savvy enough to adapt it to their own user generated content. Social networks and social interconnections are continuously expanded and enriched by new content. But since this environment is very much designed with the younger user in mind they constitute features and supporting tools that are suitable for younger generation. As such, these facilities are difficult to align with seniors' needs, which makes seniors wary and feel excluded from the intented applications. Although some social networking initiatives for seniors are emerging, we are still quite far from exploiting the potential of these technologies in ageing well.

For the ePAL roadmap, senior professionals include knowledge workers who apply intellectual capacities in creation/processing of information, as well as other professionals who use computers in their daily activities. Advances in communication media, e.g. the use of mobile devices can play a significant role in enhancing the general remote working, for all members of the society. But, through ePAL's technological perspective, we narrow down on a few main challenges specific to the senior professionals and their continuation of work. From the point of view of the technological perspective, three pre-conditions are specified as required for the success of extending professional active life of seniors, including:

- Availability and use of computing resources e.g. pervasive computing and communication links for all senior professionals must be supported.
- Establishment of virtual communities of seniors to work together on solving emerged problems in the market/society, and performing individual and/or joint tasks.

- Provision of advanced ICT technology and support tools targeting senior professionals and their working/ co-working.

The roadmapping strategy of the ePAL has identified four fundamental ICT related areas in need of further research and development for support of the specific requirements and characteristics of senior professionals and their continued enjoyable active working and coworking, namely:

- Collaborative Networks. Specification of a reference model for ePAL environment to capture all its endogenous elements (i.e. components, structure, functions, and behavior governance), as well as the exogenous interactions (with the constituents, market, society, and support providers). This model is required to facilitate the study, understanding and developments for ePAL.

- Affective Computing. Design and prototyping tools and systems to support the needed functionality and operation, with specific attention on behavioral aspects of senior professionals and ePAL communities.

- Soft Computing. Design new approaches and tools to on one hand reduce risks and frictions, and on the other hand boost and motivate collaboration and co-working among ePAL stakeholders. Here the issue of trust, mediation, rewards and incentives, value systems, etc. comes up which all deal with incomplete and imprecise information, and thus their soft modeling and qualitative analysis are required.

- Machine Learning. Specification of models and tools assisting seniors to leave their legacy behind, learning from their practices. Designing new tools for decision making through learning from past experiences and through ranking solutions with pre-defined indicators.

This document mainly focuses on the survey of promising technologies for ePAL communities, which in one way or another can be used to smoothen and facilitate the involvement of retired professionals in daily society activities. It also addresses a number of challenges in need of future work on these promising technologies in support of effective operation of communities of retired professionals.

There are a number of new ICT technologies and advances which show to certain level, the potential to facilitate the extension of professional active life amongst seniors (Afsarmanesh and Msanjila 2010), (CamarinhaMatos et al. 2010). However, at present on one hand, 
sustainability of existing freeware technologies is not clear and on the other hand there is a real need for their advancement to be steered towards the needs of senior professionals. In order for advances in ICT systems to have the desired effect they should be developed with a proper understanding of the needs of those who will be using them (Lundberg 2007). This may seem an obvious point, but it would appear important that the technological aspects of ePAL advance in parallel with its societal and organisational models. In a highly competitive industry which develops at a rapid pace applying a constantly updated line of ICT services in which new advances quickly become redundant, would mean too much of a barrier to its normal development. One solution to this problem, which is very much in line with current technological trends, is to offer a high degree of built-in adaptability to new technology. Advances in "configure yourself" technology and support systems for user generated knowledge content, along with easily customizable interfaces are crucial to allow brokers and senior professionals themselves to react to changes in a non static marketplace (Hernandez-Encuentra et al. 2009). Where seniors are working with younger professionals, adaptable technology would have to be compatible with senior's ability to use them, and not alienating senior professionals from their co-workers.

The introduction of new working patterns, when relying for instance on remote collaboration of teams of senior professionals who interact with brokerage entities and customers, introduces the need for provision of new infrastructure functionalities and supporting tools.

\section{Roadmapping framework}

The challenges posed by an ageing society have been thoroughly discussed, particularly in terms of care needs and social costs (WHO 2002). Most R\&D efforts in this area, both past and present, have adopted a reactive strategy while trying to mitigate the problems "after" the elderly reach a critical phase in dependency (Aguilar et al. 2004), (Vontas et al. 2009). ePAL however adopts a proactive strategy, identifying measures of a more "preventive" nature.

Three main elements need to be defined in a research roadmap: current situation and trends (i.e. the baseline), desired vision, and plan of R\&D actions (Camarinha-Matos and Afsarmanesh 2009). Being naturally difficult to forecast the future, and even to understand all interdependencies among the driving forces of the society, a meaningful roadmap needs to be the result of contributions from relevant visionaries and stakeholders in the field. In order to properly integrate and put in the right context the various contributions of the participants in this process, it is important to follow a set of systematic steps. Most literature on roadmapping is focused on presenting specific roadmaps, giving little hints on the followed method. In fact, one of the most prevalent approaches seems to mainly rely on the organization of discussion workshops with a considerable number of stakeholders, expecting, in this way, to extract relevant conclusions. Our roadmapping method, on the other hand, is adapted from the "standard" scientific method and has proven to be effective in various projects (Camarinha-Matos and Afsarmanesh 2004), (Camarinha-Matos et al. 2010), consisting of 10-steps:

1 Characterize and consolidate the baseline

2 Perceive trends and design scenarios

3 Elaborate a first vision statement and instantiations

4 Fill the gap: from where we are to where we wish to go

5 Propose a plan of actions

6 Verify the planned actions

7 Plan the timing and other characterization of actions

8 Finalize the definition of the roadmap chart

9 Perform consultation and refinement

10 Perform roadmap consolidation

The elaboration of a plan of strategic actions is a fundamental step in roadmapping. Such actions, when successfully implemented, shall take the society from its current situation to a desirable future, as stated in the proposed vision. The proposed vision statements and strategic actions plan resulted from a multi-stage construction and validation process. An initial formulation was prepared by the ePAL consortium following a series of consultation workshops and brainstorming sessions. Once a set of strategic actions emerged as a result of the brainstorming exercise, it was then necessary to proceed with a verification of those actions. More than 180 experts from different fields were involved the the roadmapping process, namely in the consultation and refinement phase. More details on the ePAL roadmapping approach and results are addressed in (Camarinha-Matos et al. 2010).

\section{Perspectives of ePAL communities}

Current practices indicate that the European society is still slow to recognize the rationale behind, and the importance of fully supporting the extension of active professional life of seniors (Leonard et al. 2009). The study on visioning and gap identification in ePAL addresses relevant technological, societal, and organizational factors which constitute the three orthogonal perspectives of ePAL communities (Leonard et al. 2009). It also addresses the main external influences which have the potential to impact successful future life of elderly population. These three perspectives of the ePAL environment were formulated following an extensive envi- 
ronment analysis and categorization, as well as validation (by both experts and senior professionals) of trends and drivers that show the future direction for inclusion of seniors in daily societal activities (Afsarmanesh et al. 2009). The three perspectives of the ePAL communities are addressed below summarizing some of their needed new areas of research and practice.

\subsection{Societal perspective}

The societal perspective of the ePAL vision is perhaps the most difficult to achieve, as it requires the mass mobilization of a large number of potential actors. Societal cohesion and a change in attitudes towards senior professionals are very challenging. The traditional view is that those reaching retirement age are about to make the transition to passive actors must become largely redundant due to the pan European demographic changes of an ageing EU. Recognition of the new role that can be played by senior professionals is vital for EU governments and senior professionals themselves. Societal cohesion is an important area of consideration as the rise of the senior workers will not happen in isolation. The whole society needs to be involved in keeping senior professionals active as well as defining their roles in daily societal activities without contradicting the existing regulations. As an ever increasing percentage of the EU society, seniors' contribution to their society needs to grow. To ensure that the potential of this contribution is properly coordinated, new mechanisms which gather consensus and outline the role of seniors in EU will need to be created. It is important that such mobilization does not lead to the ghetto-isation of seniors and become a source of division within the EU society.

Seniors and those just starting employment will have to learn to work together and effectively communicate. As a part of this there must be a greater understanding of the new needs this will create and new forms of leveraging the capabilities of seniors. At the same time "seniority" (position in a company) within a business environment will no longer be so closely linked to age. Maureen Minehan, (Minehan 1997) as early as 1997 noted a trend that older workers will have to accept this situation, where "seniority" becomes more linked to performance rather than age. Today, human resource departments are increasingly accepting that new forms of health and other benefits needed for senior workers to attract good employees. Recent studies show that many senior professionals still consider themselves to be discriminated against in the workplace and some employers are prejudiced by stigmas of inadaptability and lack of learning ability when they apply for jobs (Canziani and Petrongolo 2001). Mechanisms to support cross generational interaction between seniors and younger professionals; fomenting inter- generational solidarity and understanding within the EU would improve the employment systems and creating healthy balanced employment paradigm.

\subsection{Organizational perspective}

The organizational perspective of ePAL can be divided into two main strands. The first is employment policies and regulations which will facilitate the rise of the active senior professionals. The second is mechanisms which will harness the potential of senior professionals and provide increased support and structure to their contribution to the EU economy. There is a need for a full understanding of what senior professionals, in a nontraditional role as active professionals, can bring to society. This requires in part a mobilization of social capital by senior professionals themselves supported through relevant mechanisms.

A full understanding of the needs and issues around active senior professionals can provide the basis for strategic investment into more efficient and specific forms of brokerage and support services tailored to the realities of the market, its needs and the silver economy. Such brokerage should also take into account ways of mitigating problems with cross generational communication and what are the most efficient forms of work for seniors as compared to other types of professionals. It seems increasingly likely that the extension of active life will go hand in hand with a change in the average person's career trajectory. Labor systems have attracted a lot of interest and the reduced labor rigidity and indeed the rights that such systems bring would have a significant impact on the way people work in the future. Governments will play a major role in this aspect.

Of most relevance to ePAL is the effect such labor law changes would have on the traditional divisions between pre and post retirement life. Fewer EU citizens are working long term for one employer and are incentivized to retrain themselves throughout their lives and consequently take more control of financial provision for their retirement. An accent on life long learning implies that many people will have to take time out of their active professional lives at several stages of their career, with retirement planning forming part of a more sophisticated concept of career and financial planning. Brokerage for senior professionals will need to develop a wider knowledge of how it fits into this equation. Financial services specifically aimed at senior professionals will have to do the same. However, a pool of senior talent which is used to remarketing itself would in theory, make the role of brokers in leveraging this talent to diverse sources easier. Such career fluidity would also have a consequential effect on the concept of a senior worker itself. 


\subsection{Technological perspective}

There are a number of new ICT technologies and advances which show to certain level, the potential to facilitate the extension of professional active life amongst seniors. However, at present on one hand, sustainability of existing freeware technologies is not clear and on the other hand there is a real need for their advancement to be steered towards the needs of senior professionals.

In order for advances in ICT systems to have the desired effect they should be developed with a proper understanding of the needs of those who will be using them. This may seem an obvious point, but it would appear important that the technological aspects of ePAL advance in parallel with its societal and organisational models. In a highly competitive industry which develops at a rapid pace applying a constantly updated line of ICT services in which new advances quickly become redundant, would mean too much of a barrier to its normal development. One solution to this problem, which is very much in line with present technological trends, is to offer a high degree of built-in adaptability to new technology. Advances in "configure yourself" technology and support systems for user generated knowledge content, along with easily customizable interfaces are crucial to allow brokers and senior professionals themselves to react to changes in a non static marketplace. Where seniors are working with younger professionals' adaptable technology would have to be compatible and not virtually alienate senior professionals from their co-workers.

The introduction of new working patterns, relying for instance on remote collaboration of teams of senior professionals who interact with brokerage entities and customers, also introduces the need for provision of new infrastructure functionalities and supporting tools. Such functionalities may include tools for ontology management, trust building, value systems alignment, performance assessment in collaborative environments, and distributed negotiation mechanisms, among others. The subsequent sections further addresses in details the four main concepts identified within the roadmapping process of the ePAL initiative (Camarinha-Matos et al. 2010), related to the technological perspective, namely: collaborative networks, affective computing, soft computing, and machine learning.

\section{Collaborative networks}

As a guiding work hypothesis, ePAL advocates the development of collaborative networks involving senior professionals and other supporting actors of the socioeconomic system. In line with other initiatives in related areas, e.g. eSangathan, the ePAL initiative assumes that an effective transformation of the current situation regarding retirement, and the barriers to active ageing in Europe requires the introduction of new approaches and ways to create actively contributing professional communities in society. These communities will support the elderly citizens with a framework for leveraging their talents and expertise and creating value for the benefit of the Europe's economy. Moreover, the framework would also support a balanced transition towards stepwise retirement. Taking advantage of current advances in ICT technologies and in line with current trends in several European regions, the success of extending professional active life of seniors (ePAL) requires establishing 2nd generation professional virtual communities support senior professionals with remaining active and involved (Afsarmanesh and Camarinha-Matos 2009) in the market and society. This section presents the base concepts of collaborative networks in 5.1, their relevance and applications in communities of active senior professionals in 5.2, and the specific aspects in need of further research in 5.3.

\subsection{Base concepts of collaborative networks}

A traditional Virtual Community is composed of a group of individuals that virtually come together, i.e. by means of computer communication, and stay in touch for a long period of time (Crave et al. 2006). Through Virtual Community, the members interact with each other creating personal relationships, sharing common social ties in the form of interests, feelings, knowledge, and experiences (Picard 2006). The aim in ePAL is to step beyond "socialization", and to pursue mechanisms for interaction with the socio-economic system, and therefore facilitate the use of the potential contributions from retiring and senior professionals. We are therefore addressing new organizational forms, focused on collaboration, i.e. collaborative networks whose members act together towards joint value creation.

A Collaborative Network $(\mathrm{CN})$ is a network consisting of a variety of entities (e.g. organizations, people, even intelligent machines) that are largely autonomous, geographically distributed, and heterogeneous in terms of their operating environment, culture, social capital and goals, but which decide to collaborate to better achieve common or compatible goals, and whose interactions are supported by computer network (Camarinha-Matos and Afsarmanesh 2006). Although not all, most forms of collaborative networks imply some kind of structure / organization over the activities of their constituents, identifying roles of each participant adhering to some governance rules. Therefore, the term Collaborative networked organization (CNO) is used to represent a collaborative networks with some form of organization, in terms of their structure of membership, 
activities, definition of roles of the participants, and following a set of governance principles and rules. In this document the following definition of $\mathrm{CNO}$ is adopted and applied:

A CNO is an alliance constituting a variety of entities (e.g. organizations and people) that are largely autonomous, geographically distributed, and heterogeneous in terms of their operating environment, culture, social capital, and goals, and that cooperate/collaborate to better achieve common or compatible goals, and whose interactions are supported by the computer network (Camarinha-Matos and Afsarmanesh 2006).

Among the CNOs, we can distinguish between the longterm "strategic" alliances and the goal-oriented networks. Long-term strategic networks/alliances are established to act as the breeding environments for goal oriented networks, namely with the purpose of getting their participants prepared for participation in response to collaboration opportunities. In other words, they are alliances aimed at offering the conditions and environment to support the rapid and fluid configuration of goal oriented collaboration networks, when opportunities arise. Goaloriented networks are CNOs in which intense collaboration (either towards a common goal or a set of compatible goals) is practiced among their partners, for example the virtual organizations (VOs). All CNOs aim at value creation, while the value system of each $\mathrm{CNO}$ is defined to serve the specific short or long term aims of that CNO.

In this document we address two specific forms of CNOs, namely one shorter-term type (i.e. VOs) and one long-term type (i.e. Virtual organizations Breeding Environments -VBEs). VOs represent shorter-term goal-oriented collaborations between partners, while VBEs represent long-term cooperation. Although their main actors involve organizations, the base concepts have the potential to be adopted, tuned and applied in network settings involving individuals such as senior professionals. The definitions of a VO and a VBE adopted and applied in this document are as follows:

A VO is an association of (legally) independent organizations (VO partners) that come together and share resources and skills to achieve a common goal, such as jointly acquiring and/or executing certain tasks to fulfil a market/society opportunity (CamarinhaMatos and Afsarmanesh 2006).

A VBE is defined as a "strategic" alliance of organizations (VBE members) and related supporting institutions (e.g. firms providing accounting, training, etc.), adhering to a base long-term cooperation agreement and adopting common operating principles and infrastructures, with the main goal of increasing both their chances and preparedness of collaboration in potential VOs (Afsarmanesh and Camarinha-Matos 2005).

Organizations interoperate and collaborate within VO and VBE networks while being facilitated by computer networks, in order to achieve certain common or compatible goals, such as the acquisition of and response to larger, better, and more business opportunities. As such, different kinds of co-working are applied in shorter-term and longterm CNOs and in order to further describe and distinguish between the cooperation and collaboration concepts related to CNOs, the following definitions are applied in this document (Camarinha-Matos and Afsarmanesh 2008a, b):

Cooperation, practiced in long-term CNOs, involves not only the exchange of information and alignment of activities, but also the sharing of resources for achieving compatible goals. Cooperation is achieved by the division of some minor labor (not extensive) between participants. However, a common plan exists that in most cases is not defined jointly, but is designed by a single entity (perhaps by the coordinator/administrator of the cooperation alliance), and which requires some low-level of cooperation.

Collaboration that is practiced in shorter-term goaloriented CNOs on the other hand is a process in which entities share information, resources and responsibilities in order to jointly plan, implement, and evaluate a series of activities that will help them achieve the common collaboration goal. It implies a group of entities that work intensively together and enhance each other's capabilities. It also implies sharing risks and rewards that, if desired by the group, can also provide outside observers with the impression of a joint identity. Collaboration involves the mutual engagement of participants to solve a problem together, which requires strong trust relationships and thus takes time, effort, and dedication.

Market and society continuously evolve to cope with the complexity of today's connected digital world. Therefore, the preparedness of an actor that is required to facilitate collaborative initiatives must match the evolution of market. It is more difficult to individually achieve the required preparedness for this matching. Principal aspects of preparedness and VO configuration include establishing common operating principles, acquiring an interoperable infrastructure, and creating trust between organizations, which are aimed to be provided within long-term collaborative network - such as the long term strategic alliances established as VBEs. When achieved, these aspects of an organization's preparedness enhance its chances of being able to quickly and efficiently join successful goal oriented networks. 
Previous studies have assumed that the most suitable partners for establishing a new shorter term goal oriented networks may easily be identified and selected from the open universe of available organizations, for example through the Internet, and merged into the required shorter term goal oriented networks. However, this assumption overlooks a large number of obstacles in this process, among which the following can be mentioned (Afsarmanesh and Camarinha-Matos 2005).

- How to learn of the mere existence of potential partners in the open universe and deal with incompatible sources of information.

- How to acquire basic profile information about organizations, when no common template or standard format exists.

- How to quickly establish an inter-operable collaboration infrastructure, given the heterogeneity of actors at multi-levels, and the diversity of their systems.

- How to build trust between actors, which is the base for any collaboration.

- How to develop and agree on the common principles of sharing and working together.

- How to quickly define the agreements on the roles and responsibilities of each partner in order to reflect the sharing of tasks, the rights on the produced results, and so on.
As a basic rule, supporting the dynamic/fluent formation of collaborative networks, such as in a shorter term consortium, requires its potential partners to be ready and prepared to jointly participate in such a collaboration environment, as addressed in Fig. 1. The foundation of this readiness should include reaching commonality agreements on aspects such as the interoperable infrastructure, operating rules, and cooperation. For instance, within a collaborative network, the agreed working and sharing principles may specify the frequency by which the progress of internal tasks performed by each member shall be reported to the network, and which specific data must be shared about it, and in which format. Any collaboration also requires that all involved actors meet the required level of competency and performance to be considered trustworthy by other partners. Therefore, the concepts of long-term strategic alliances have emerged as the necessary context for the effective creation of dynamic shorter term consortiums.

A main aim of the long-term strategic alliances is focused on the transition from point-to-point connections between actors to a network structure in order to increase the chances of its members' involvement in opportunities for collaboration, and to reduce the costs and time needed to configure opportunity-oriented consortiums (Fig. 1). To conclude, the transition from point-to-point connection to networked structure enhances actors' preparedness in the following aspects (Afsarmanesh and Camarinha-Matos

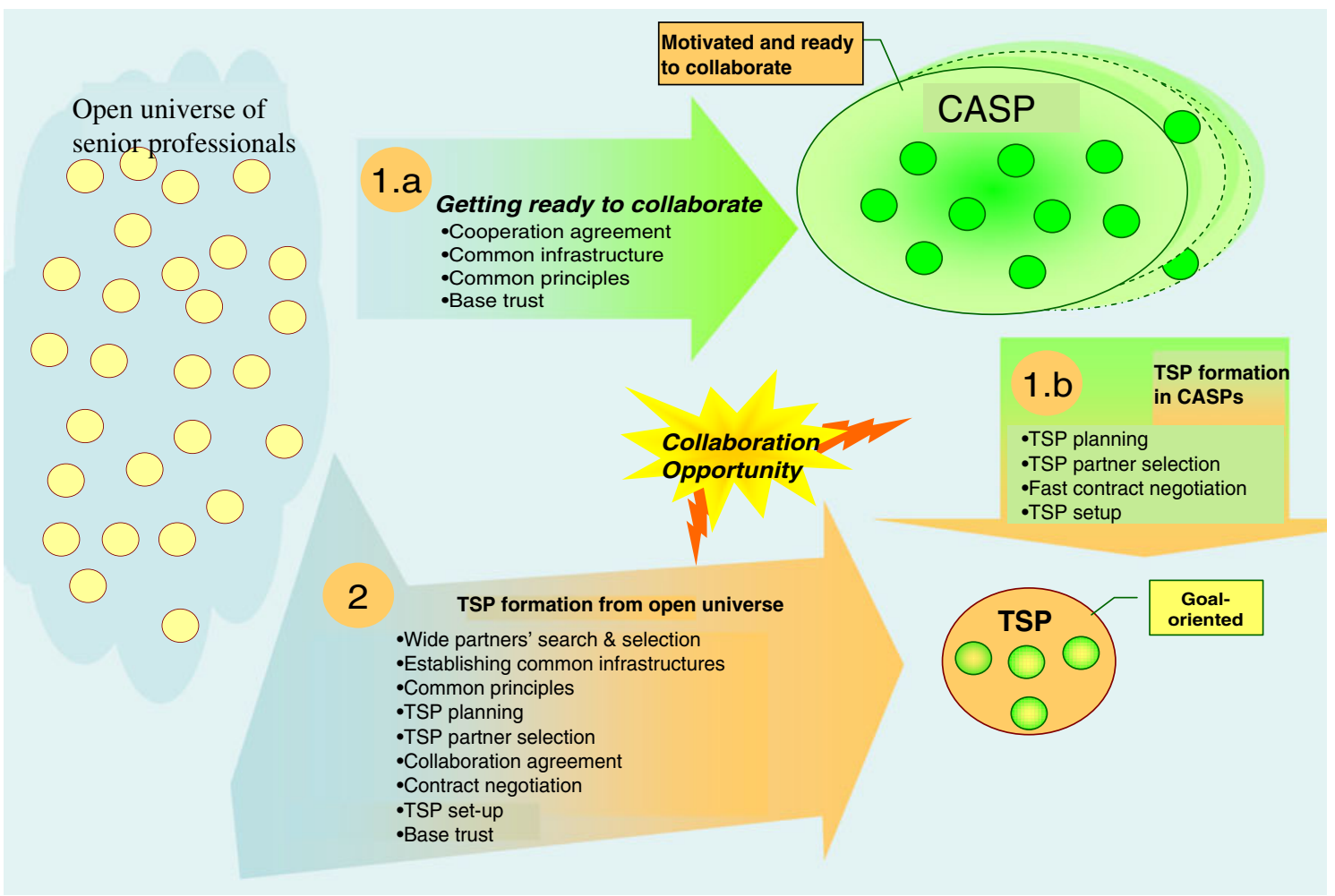

Fig. 1 Concepts from a potential ePAL environment 
2009): (1) Maintaining common sharing and operating principles, (2) Acquiring an interoperable infrastructure, (3) Achieving the same level of understanding through common ontology, (4) Defining common value systems and performance metrics, (5) Creating trust between actors, and (6) Acquiring systems for assisting the management of cooperation and collaboration.

5.2 Strong relevance of collaborative networks' concepts to the ePAL communities

Over the last two decades, many organizations and individuals have relied on virtual collaboration by forming distributed teams to achieve higher productivity and produce joint products that would have been impossible to develop without the contributions of multiple collaborators. ICT related technologies have evolved from standalone tools, to open systems supporting collaboration in multiorganizational settings, and from general purpose tools to specialized collaboration tools. ePAL communities can be established on the basis of concepts related to collaborative networks. While characterizing the collaboration among senior professionals we have introduced the following terms related to collaborative networks of senior professionals to support characterization of the ePAL communities (Afsarmanesh et al. 2009).

CASP (Community of Active Senior Professional) constitutes an association of senior professional individuals that are largely autonomous, geographically distributed, and potentially heterogeneous in terms of their: capabilities, offered capacities, culture, system of values, etc., but sharing their main compatible and/or common goals of increasing their active professional life in the society and/or market, through co-working with others in Teams of Senior Professionals supported by computer networks, under the slogan of: "Together Everyone Achieves More!".

TSP (Team of Senior Professionals) is a collaborative network of individuals configured and established within the CASP in response to opportunities in the society and market that are in need of their wisdom and/or knowledge assets that they can offer, which as a consequence supports the retired professionals remaining professionally active.

SP (Senior Professional) is a retired professional who becomes a member of CASP in order to increase his/her chances of staying active and involved in the socioeconomic system, and perhaps also through getting involved in potential TSPs established through the CASP.

Individuals decide to join and collaborate in professional communities when they are convinced that they can achieve more by co-working with others. Such achievements may include: optimizing their business profits, improving their knowledge and skills, complementing themselves with missing resources and competencies. The advantages of the geographical and societal widening are in this respect evident: the widest the social and geographical spread, the highest the possibilities for the individuals to reach their objectives.

An association of retired professionals can represent a special form of a professional virtual community in the sense that it is a community constituting individual senior professionals as members. The establishment and management of such alliances of individuals can benefit from well researched and developed concepts and tools for professional virtual communities. Most collaborative networks are business oriented entities, particularly focusing on supporting their members to jointly optimize individual financial gains. Therefore, the focus of associations of retired professional is not necessarily enhancing the financial gains of members. Rather to keep and enhance the professional active life of their members. With support of CASPs senior professionals can remain professionally active and thus involved in the society. These seniors are willing to transfer, share and exchange their knowledge and experience to those individuals or organizations that are in need. There are two challenges that retired professionals are facing when providing their services in terms of bundles of knowledge and experience to beneficiaries, as described below:

- Opportunity brokerage-Finding opportunities to apply their knowledge and experience-i.e. beneficiaries willing to accept their offers - is quite challenging. From our empirical study it was observed that many retirees within existing CASPs face difficulties when trying to individually acquire opportunities in the society such as consultancy, since those are also being targeted by other formal service providers. Even when such opportunities are brokered for senior professionals, the process of building trust and credibility for the individual retirees in the eyes of the beneficiaries might be very challenging.

- Opportunity complexity-Most acquired opportunities cannot be responded by one senior professional alone. For example, SMEs which need consultancy on a subject typically require more than one kind of expertise need a number of seniors to collaborate, in order to provide the required services.

5.3 Further required research on collaborative networksapplicable to ePAL environments

Solution for challenges related to future collaboration, to enhance a fully realization of promises of electronic coworking, require advancements in networking technologies, tools and systems, user interfaces and interaction paradigms. It also demands, advanced interoperation between 
application-specific components and generic supporting tools. Below we present some topics in need of further research in relation to application of concepts related to collaborative networks namely CASPS and TSPs to ePAL environment.

\section{(i) Specification of formal conceptual models for profes- sional life cycle of people and the support environ- ment for active ageing}

In research, there is still lack of suitable formal conceptual models to support regulating people's professional active life-cycle. It is essential to establish a reference model for the extension of professional active life and active ageing, The model should incorporate the elaboration of a common ontology for the senior professional communities. Another component that must be supported is the development of contractual and business models for CASPs. As such, in relation to development of formal conceptual models, the following need to be further addressed:

- Development of conceptual models to support designing and implementing collaboration support services, including services supporting (virtual) teams' formation and management that are user friendly to senior professionals;

- Discovery and management of collaboration ontology that supports a variety of stakeholders in CASPs and configured teams of senior professionals;

- Design of templates for novel contractual and cooperation agreements, as well as designing models to support the implementation systems supporting negotiation among senior professionals;

- Development of models to guide the implementation of advanced marketing and brokerage services;

- Designing new networking models for elderly communities' involvement with the socio-economic system.

(ii) Development and integration of self-adaptive and configurable technology solutions in ICT environments, to enable customized involvement of seniors

Self adaptive and configurable technology is able to evaluate its own behavior and change its behavior to improve itself based on its present evaluation result (Laddaga et al. 2003). For example, it can change its behavior to improve its performance when evaluations result indicates that it is not accomplishing what the technology is intended to do, or when better functionality or performance is possible (Osterweil and Clarke 2001). Thus the technology also modifies its behavior in response to changes in its operating environment-e.g. end user input, availability of external hardware device, etc. This implies that the self-adaptive technology, such as a computer system, has multiple ways of accomplishing its purpose, and has enough knowledge of its construction to make effective changes during runtime. Such technology should include functionality for evaluating its behavior and performance, as well as the ability to re-plan and reconfigure its operations in order to improve its operation. Self adaptive technologies should also include a set of components for each major function, along with descriptions of those components, so that components of the systems can be selected and scheduled at runtime, in response to the evaluations. It also requires the ability to match input/output of sequenced components, and the ability to generate some of this code from the specifications.

There are some seniors that may require special training and assistance when dealing with technology. It is thus desirable and/or necessary to have self-customizable tools supporting collaboration operations that empower seniors to better use the provided ICT solutions. For this challenge a number of technical solutions may be developed, such as: self-adaptive interface systems and technology assistance wizards. To deal with emerging technologies, seniors should also have access to several training modules. In relation to this topic further research is required to address the development of "Configure yourself" -based infrastructure, and easily adaptable and customizable user interfaces. Relevant and challenging aspects in this area that are in need for further research include the following topics:

- Identification of generic and customizable indicators for measuring the performance of systems/tools during runtime;

- Design and development of mechanisms supporting systems to make decision regarding changing their behavior based on collected performance data;

- Development of affective/emotional tools to detect and discover state/status of interactions between systems and senior professionals (addressed also later).

(iii) Development of ICT collaboration platforms, enhanced by affective computing, context awareness, and trust establishment, to support operations of CASPS

ICT collaboration platform offers a set of software components and software services that enable actors to find each other and the information they need to be able to communicate and work together to achieve common business goals. Its core elements typically include: email, calendaring, scheduling and contacts, file synchronization, wiki of ideas and notes, task management, full-text search, instant messaging, web conferencing, application / desktop sharing, voice, audio and video conferencing, blog, wiki, tagging, RSS, shared bookmarks, etc. as initiatives such as 
eSanghatan project (Turbe-Suetens and Kouloumdjian 2009) have also investigated.

In the context of CASP it is of extreme importance to be supported with an ICT collaboration platform for communities of senior professionals. Such a platform, besides providing the basic required services (as addressed above) constitutes part of the governance systems of this community. Thus, it should also provide operational services/tools such as an advanced management system for CASP, a trust building management system, together with users/community affections / emotions management system. To realize a proper ICT collaboration platform for senior professionals, further research need to be performed addressing the following:

- Development of advanced collaboration support services, including (virtual) teams' formation and management,

- Development of affective computing and context aware enriched environments,

- Formulation of mechanisms and development of systems supporting the establishment of trust among stakeholders,

- Provision of security and ethical / privacy support.

(iv) Design and development of support collaborative tools and systems to facilitate value creation in CASPs environment

For ePAL, effective marketing is essential to the success of business brokerage. Communities of senior professionals should be supported to assess their business climate and capabilities in order to enhance their identity of brokerage brand through marketing strategies. Such strategies may include advertising, public relations, customer service efforts, etc. Considering the current advancement of technologies, supporting collaboration among actors, marketing related processes require to be properly supported by collaborative tools and systems to enhance their effectiveness. Therefore, in order for collaboration platform to enable its community members in performing their professional activities, it must provide facilities and tools for the following processes: (1) Marketing and brokerage, (2) Virtual Team creation, (3) negotiation and e-contracting, (4) Virtual Team management, (5) collaborative problem solving support, and (6) Intellectual Property and performance management, etc.

Furthermore research needs to be performed to address the development of the tools and systems supporting the following:

- Advanced collaboration support services, including (virtual) teams' formation and management,

- Tools supporting the process of value creation,

- Advanced marketing and brokerage services,

- Security and ethical / privacy support.

\section{Affective computing}

The establishment of CASPs is based on the premise that 'professional society' and senior professionals can mutually benefit from actively re-involving retirees in the economic process. Technology might be used to bridge the gap between retired professionals and organizations by providing facilities to create contact, collaborate and recognise needs on both ends. However, only focusing on the provision of functionality to facilitate cooperation is not enough. Rather, motivating all parties and ensuring a positive experience will be just as crucial for professional interactions among these age groups.

Retirees are not obligated to work, nor are organizations obliged to include retirees in their daily work practice. For this to be realized both retirees and organizations need to perceive value in continuing participation. Any technology used to facilitate active ageing will have to be designed taking into account a selection of social and affective aspects of interacting with computers and each other online (Cramer 2007). Examples of such affective aspects include:

- Targeting and managing (online) individual identities,

$\circ$ Adapting to the specific needs of the individuals on both ends,

- Matching organizations and professionals,

- Overcoming challenges of online communication, (v) Fostering feelings of inclusion and value,

- Establishing trust in the technology used, trust in eachother and trust in one's own ability to contribute.

Of particular importance in relation to affective computing is that it can facilitate capturing emotions of the technology users, so that through addressing those emotions the usability of the system and thus users interactions can be enhanced. Senior professionals are at the age when they may typically feel isolated and excluded from the society they served for their entire lives, and sometimes they might have the so called 'bad days'. If the technology can capture those emotions and respond to them in a timely and positively perceived manner, it could encourage the seniors to virtually engage themselves in society activities. In relation to these requirements a number of topics in this area need to be thoroughly addressed by research as introduced in Sections 6.1, 6.2 and 6.3.

\subsection{Base concepts of affective computing}

Affective computing deals with emotions. Emotions themselves are very human matter, of which there is no clear theory or understanding related to how they are created or how they evolve. However, affective computing could provide massive improvements in human-computer interaction, in the form of usable and intuitive interfaces (Picard 
2006). Machines and software could adapt their behaviour to human. Because emotions and rational intelligence are very intertwined in humans, it could be believed that emotions are a prerequisite for truly intelligent computers (Karuppiah et al. 2001). By building affective computers we could make computers friendlier and advance towards the promises so far not yet achieved by the field of artificial intelligence. However, a lot more need to be done in research and development to advance the current achievements in relation to affective computing, to match the exact needs in the market and society today.

Affective Computing is computing that relates to, arises from, or deliberately influences emotion and other affective phenomena. The field was originally named and defined treating affect and emotion essentially synonymously, and there is still no widely agreed upon definition of either the term "emotion" or "affect" in the literature; however, there is a general acceptance that affect is the broader term, and that states such as "interest" are affects, whether or not they are emotions, while states such as "anger" are both an emotion and an affect. Affective computing deals with the design of systems and devices that can recognize, interpret, and process human emotions (Lee et al. 2001). It is an interdisciplinary field spanning computer sciences, psychology, and cognitive science. While the origins of the field may be traced as far back as to early philosophical enquiries into emotion, the more modern branch of computer science originated with Rosalind Picard's 1995 paper on affective computing (Picard 1995). A motivation for the research is the ability to simulate empathy. The machine should interpret the emotional state of humans and adapt its behavior to them, giving an appropriate response for those emotions.

Therefore, affective computing thus addresses the issues regarding emotions and computers. The most prominent research questions of the field are: What is the foundation of recognizing, understanding and expressing emotions? How do emotions interact with intellectual processes? How can we build a computer able to feel? Nevertheless, various application cases have been identified and experiments are being performed (Tao and Tieniu 2005). Regardless of the resolution of the precise definitions of emotion and affect, research in Affective Computing addresses the broader sense of the two terms, and contributes to Artificial Intelligence, Pattern Recognition, Machine Learning, Human-Computer Interaction, Social Robotics, Autonomous Agents, Cognitive and Affective Sciences, Affective Neuroscience, Neuroeconomics, Health-behavior Change, and many other areas where technology is used to detect, recognize, measure, model, simulate, communicate, elicit, handle, or otherwise understand and directly influence emotion and other affective phenomenon.
The latest scientific findings indicate that emotions play an essential role in decision making, perception, learning and more. They influence the very mechanisms of rational thinking. Not only too much, but also too little emotion can impair decision making. According to Rosalin Picard (Picard 1995), if we want computers to be genuinely intelligent and to interact naturally with us, we must give computers the ability to recognize, understand, and even to have and express emotions.

Emoticons have been around since the beginning of the textual communication. They are a proof of the people's need to express themselves emotionally, in any type of interaction, being that for business, personal or any other purpose. Moreover, they act as a proof of the need to 'inject' emotions to the communication in platforms supporting operations of collaborative networks. Emotions can influence the experience of the participants in collaborative environments, increase the achievement and performance level, motivation, excitement in interaction with each other and the whole perception among individuals. The quality of the collaboration and the output might directly depend on the creativity of the members of the collaborative network. According to the "broaden-and-build model' (Fredrickson 2003), positive emotions play a key role in increasing an individual's creativity. Moreover, emotions can control the motivation for achieving goals as well as improving a person's problem solving ability. Through emotional communication an individual can develop empathy towards the other participants in the collaboration. Many researchers consider empathy to be a strong mechanism for reducing frustration and generally improving the emotional state and mood (Karuppiah et al. 2001). We argue here that empathy is one of the missing aspects that differentiate communication in collaborative networks from direct physical human-human interaction, an aspect that brings closeness, trust, naturalness and pleasantness into the communication (Lee et al. 2001). The expression of emotion, feelings, and mood in a mediated interaction has been considered as a defining characteristic of "social presence" (Lee et al. 2001). Advancement of affective computing technologies and ubiquitous computing enable realization of the notion of social presence with focusing on the participants of the collaborative networks and placing the computer-mediation process in the "background".

Main affective communication (expression) channels are considered to be the visual (facial expressions and body gestures) and audio (speech and other sounds). Additionally, with the use of specific monitoring sensors internal physiological reactions can be a useful indicator of the emotional state. Monitoring of human reaction and recognition of correct emotional state enables emotional awareness and can result with more successful interaction and 
collaboration. Emotional intelligence as well as intelligent emotional expressiveness require natural (preferably visual), proper and human-like expression. Emotionally expressive avatars (virtual human like characters) can be used as an interaction instrument in collaborative networks. They can act as a visual representation of the individual on the other side of the communication. Through avatars one can better understand the current emotional state of the other person, easily relate to him/her, show empathy towards the person (not the avatar itself) and by that help in reducing one's frustration (Aggarwal and Cai 1999). External parameters such as behavior, societal interaction rules, current situation etc., influence the extent of the emotion expression.

Related to affective computing other important issues include persuasion (any interactive computing system designed to change people's attitudes or behaviors), useradaptivity (adapting to affect/motivation and retirement stage interface for knowledge level), identity and role (active ageing involves ever-changing roles), and societal context (interaction of the retired professional and system are not without a societal context of peers, 'customers'/ team mates, support system).

\subsection{Relevance of affective computing to the support} of ePAL environments

An affective computing system addresses the ability to sense users' biosignals as well as recognizing the patterns inherent in users' interactions, then using these, an understanding module can assimilate these data into a model of the user's emotional experience. For the ePAL environment, the relevance of affective computing shall be demonstrated when such requirements are fully supported by the related system. Seniors have emotions that a developed system shall require to capture, analyze and understand, in order to avoid irritating experiences and enhance preferred experiences. The fundamental application of affective computing to the ePAL environments shall emerge in the next-generation of human interfaces which must be developed with capabilities to recognize, and respond to the emotional states of senior professionals.

6.3 Further required research on affective computingapplicable to ePAL environment

In short, taking into account the characteristics of the involved individuals, their societal context and (affective) experiences involved in the mutual cooperation-without relying on pre-existing assumptions about these concernscould prove key in the success of collaborative technologies that facilitate active ageing. (i) Development of approaches that discover patterns and model "the evolution of senior professionals' interests and their involvement in the socio-economic system" and "the behavior and emotional health of senior professional networks".

Behaviors of people at certain point in time are influenced by characteristics of the environment in which they are operating, which in turn influence the people's interests and decision on performing certain activities. Specifically for communities of active senior professionals, further research is needed to enhance the development of a conceptual base for behavioral modeling, data-mining / machine learning approaches for behavioral patterns discovery, forecasts and simulation methods and tools for behavioral analysis. Furthermore, models and tools need to be designed and developed for supporting management of emotional health of collaborative networks. In relation to this topic further research should also address the following among others:

- Develop approaches to characterize emotions and define necessary differentiating indicators,

- Development of easily adaptable and customizable user interfaces that are emotionally supportive,

- Development of tools supporting affective computing and that are context aware enriched environments,

- Formulation of mechanisms and development of systems supporting the establishment of trust among stakeholders,

- Design of new networking models for elderly communities' involvement with the socio-economic system.

(ii) Development of approaches and tools providing support for sensing and recognition of emotions of SPs

The range of means and modalities of emotion expression is so broad, with many of these modalities being inaccessible and many others being too non-differentiated. This makes it difficult to collect the necessary data to perform the required affective related computation. In fact, people's expression of emotion is so idiosyncratic and variable, that it is challenging to accurately recognize an individual's emotional state from the available data. This subject still needs further research and development in both aspects of affective computing technologies, such as automated systems, and hardware, such as sensors.

(iii) Design and development of modelling approaches and tools for seniors' emotions and their related evolutions

There is still a lack of suitable models developed to support the design of required affective computing related 
systems, and not enough progress has been made with cognitive modeling. While some data exist regarding the effects of emotion on decision making and behavior, the majority of these data were collected in highly artificial environments, such as laboratories, and both their robustness and application seem to fit the need of academic and research needs but not for empirical need in real life. Existing models of emotion use highly stylized stereotypes of personality types and emotional responsiveness, which do not correspond to real behavior in people. Together, these factors make it difficult for any existing single modeling approach and/or tool to provide valid models of emotional processing. This indicates that although affective computing is promising in facilitating involvement of senior professionals in societal activities, once the emotions are captured and incorporated in system, more research related to modeling emotions and their evolutions needs to be done.

\section{(iv) Design and development of tools and systems that can process and simulate the evolutions of emotions of senior professionals to support prediction of possible future behaviour}

Upon collecting data regarding emotions of senior professional an extensive analysis is needed to understand their evolution with time. The examination of this data should include simulating different scenarios to predict possible future behaviour and emotions of senior professionals. With proper simulation results and well defined scenarios an analysis can be done to identify indicators that can be used to show the cause of changes in emotional and behaviour of senior professionals. To enhance the effectiveness of these processes proper tools and systems need to be designed and developed which are aspects that need further research.

\section{(v) Development of interfaces for displaying, communi- cating, mediating and expressing SP' emotion}

Technology can easily give the appearance of having emotions without having the components that traditionally accompany biological emotions. In other words, technology to send affective information-portraying affect through some modality - might be possible to build. However, the hardest challenge in real-time interaction is figuring out when to communicate which affect. Without understanding social display rules and other important cues about the interaction context, technology is quite likely to irritate people with its emotional outputs.

Furthermore, the difficulty of communicating emotions between two nodes through text-based online interaction has led to the development of emoticons and other means for people to add affective intent. The extents to which these attempts are based on well formulated principles and actually work to properly communicate emotion are topics in need for further research.

It is clear that the sine qua non of emotion expression is the reaction visualized by the physical body of the respective human being. The challenge is representing those reactions in computer systems taking into account that these systems do not have physical bodies like those of human beings. Existing attempts at expressing emotions in robots, which are at times referred to as embodied are unable to generate the type of affective responsiveness characterizing human-human interaction (Cramer 2007). Therefore, there is still a wide open area related to expressing human emotions in a language that is understandable by both human being and compute systems.

Moreover, some people prefer non-affective interaction with computers and do not wish for computers to communicate social-emotional signals. Affective computing designers can honor this preference by designing such aspects of control or adaptation. Since a driving principle in the development of affective computing is to honor people's affective preferences in the technology design, the preference of "show me no affective communication" should be accommodated. How will systems automatically reconfigure themselves to react to such situations is a topic also in need for further research.

\section{(vi) Establishment of affective computing related ethics for SPS}

In real life, emotions, perhaps more so than thoughts, are ultimately personal and private and thus people are not willing to see their emotions documented especially when they visualize those people negatively (Aggarwal and Cai 1999). Any attempts to detect, recognize, not to mention manipulate, a user's emotions thus constitutes the ultimate breach of ethics that will be difficult to be accepted by computer users. Thus in relation to ethics, further research needs to be done to find ways on how ethical rules can be tuned to facilitate the adoption of affective computing in daily life activities.

Researchers addressing affective computing focus on technical challenges of making systems that can send, sense, intelligently handle and simulate affective information. While addressing those challenges researchers should not fall prey to the common scientific tendency to make something just because it can be done. An ever present challenge is to work together with people from diverse backgrounds, accepting and giving constructive criticism on new findings, and seeking public input to steadily discern what should be done in developing technology to improve human experience in relation to affective computing.

Although affective technologies enable a wide variety of interesting new and beneficial advances, the technological 
power to sense, measure, monitor, communicate, influence, and manipulate emotion could also be used for harmful or otherwise undesirable purposes. Any new technological capability raises societal, ethical, and philosophical questions, and research needs to be performed to address ethical issues that are related to emotions with respect to the new capabilities this technology brings. A key challenge here is related for example to when technology is "sending" a person's affective information, should what is sent always be under the sender's control, and if so, how do you give a person control over what they send without over-burdening their interaction?

\section{(vii) Intelligent and respectful system responses to perceived emotions for SPs}

When a person reveals affective information to a recipient, the recipient can choose ways to respond that may be helpful or harmful. For example, if a person lets a computer (robot or agent) know that its action is very frustrating then the computer could try to recognize its gaffe and take steps to avoid it in the future. It could issue an acknowledgement of the frustration it has caused, and perhaps even apologize, and see if this helps alleviate the person's frustration. Sometimes it might be appropriate for a computer to display an empathetic or caring response. Computer-provided empathy can reduce frustration and stress and can impact perceptions of caring, which could help in health-care technologies, among others. The challenge in relation to these issues is on how they will be addressed and incorporated in systems used for affective computing.

\section{(viii) Design and development of affective qualified collaborative systems that are user friendly to senior professionals}

Every senior professional can achieve more and better when participating in collaborative teams that working alone. The introduced concepts of CASPs and TSP in this document demonstrate the need for well configured and supported collaboration among senior professionals. For this purpose collaborative systems need to be designed and developed taking into consideration the usability and provided functionalities that are suitable to senior professionals.

\section{Soft computing}

The development of CASPs with an active involvement in the socioeconomic system represent a complex case whose proper understanding, design, implementation, and management require the integration of different modeling perspectives and techniques. The advances in soft comput- ing may lead to the creation of more flexible software that can adequately help researchers to deal with modeling complex systems that are related to ePAL communities. As a specific form of collaborative networks, CASPs are also characterized by their increasing levels of uncertainty, complexity, and heterogeneity, which are the complexities now addressed under soft computing.

Soft computing differs from conventional (hard) computing in that unlike hard computing, it is tolerant of imprecision, uncertainty, partial truth, and approximation. In effect, the role model for soft computing is the human mind (Msanjila and Afsarmanesh 2008). The guiding principle of soft computing is: exploit the tolerance for imprecision, uncertainty, partial truth, and approximation to achieve tractability, robustness and low solution cost (Abraham et al. 2007).

Behavior, interaction, and decision making of senior professionals are influenced by a large number of factors. For example, in addition to emotions, factual data as well as past experiences influence the decision making process in human. However, many of these factors can typically not be measured by numbers. Furthermore, the unmeasurable factors aldo do influence on the measurable factors. For senior professionals, issues such as how to measure as well as analyze their trustworthiness and readiness to collaborate, requires the use of both measurable and unmeasurable factors. Nevertheless it is not possible to precisely and completely collect the values of all these factors. In such situations, in order to correctly assess the suitability of potential senior professionals, soft computing approaches can be applied to support making decisions with imprecise and incomplete data. A number of research topics in this area need to be addressed for ePAL, as discussed in Sections 7.1, 7.2 and 7.3.

\subsection{Base concepts of soft computing}

Perspectives related to behavior and decision making in face of incomplete and imprecise information are particularly difficult to model (Msanjila and Afsarmanesh 2008). In fact, this context involves a number of autonomous and heterogeneous entities - organizations and people - often with: (1) different value systems, and therefore different perceptions of value and importance / priority of things, and (2) a behavior influenced by factors such as emotions, health / physical status, preferences, working habits, ethical values, level of trust, competences, etc.

Some of these aspects have a socio-organizational and anthropocentric nature that is difficult to capture with traditional logic modeling approaches. In these systems it is necessary to consider that (Msanjila and Afsarmanesh 2009): (1) Different entities have their own individual agendas and goals, sometimes conflicting with each other; 
(2) It is difficult to collect / share information on a timely fashion, even though parties might have agreed to do so; (3) Some parties might omit relevant information or even lie for their own benefit; and (4) It is often difficult to make explicit all relationships, roles, and principles followed in a network, (5) It is challenging to capture social-networking at personal level that often happens in multiple dimensions in background and overlapping (if not dominating over) the foreground (basically explicit) network structures.

Nevertheless, and in spite of these difficulties, entities involved in a collaborative network need to plan and make decisions in scenario cases with incomplete and imprecise information (Msanjila and Afsarmanesh 2008). This raises the need for: (1) Modeling approaches and developing models to represent such contexts; and (2) Reasoning techniques for decision-making in contexts of incomplete and imprecise information.

Other dimensions of this problem area include "complexity", what researchers try to capture with the notions of nonlinear models, emergence, self-organization, etc, as well as the "dynamism" of the networks in terms of their "shape / topology" (membership, roles, distribution in case of mobility). Soft modeling methods can exploit the tolerance for imprecision, uncertainty, and partial truth, and are therefore promising candidates to deal with the issues addressed above.

One characteristic of soft computing is the intrinsic capability to create hybrid systems, combining two or more soft computing (SC) methodologies to benefit from consequent synergistic effects (Msanjila and Afsarmanesh 2008). Such arrangement provides complementary reasoning and searching methods that allow combining domain knowledge and empirical data (e.g. training data sets) to develop flexible computing tools and solve complex problems. Figure 2 illustrates a taxonomy of these hybrid algorithms and their components. This figure shows the main area of research and their sub-areas (research components) of soft computing whose results can generate valuable input to solving ePAL challenges of a soft nature. The figure also shows at the lowest level of its hierarchy the interrelations among various components from different main areas of research. The relevance of these main research areas of soft computing to the ePAL environment is addressed in Section 7.2.

Some typical application areas of soft computing are data mining, pattern recognition and classification, optimization, decision support systems, and control systems. A study of applicability in collaborative networks, including an extensive set of case studies can be found in (Camarinha-Matos and Afsarmanesh 2008a, b). Soft computing includes both the "modeling" of imprecision, partial truth, and uncertaintyalso referred to as soft modeling — and the "reasoning" and inference based on such models - also referred to as soft reasoning. Therefore, Soft computing refers to soft modeling plus soft reasoning.

In addition to the classical methods of soft computing as the ones mentioned above, there are other approaches with potential applicability in dealing with vagueness. One example is qualitative reasoning, which creates simplified representations for continuous aspects of the world, such as space, time, and quantity, which support reasoning with very little information (Salles and Bredeweg 2006). It is motivated by two observations, namely:

- People draw useful and subtle conclusions about the physical world without differential equations. In our daily lives we figure out what is happening around us and how

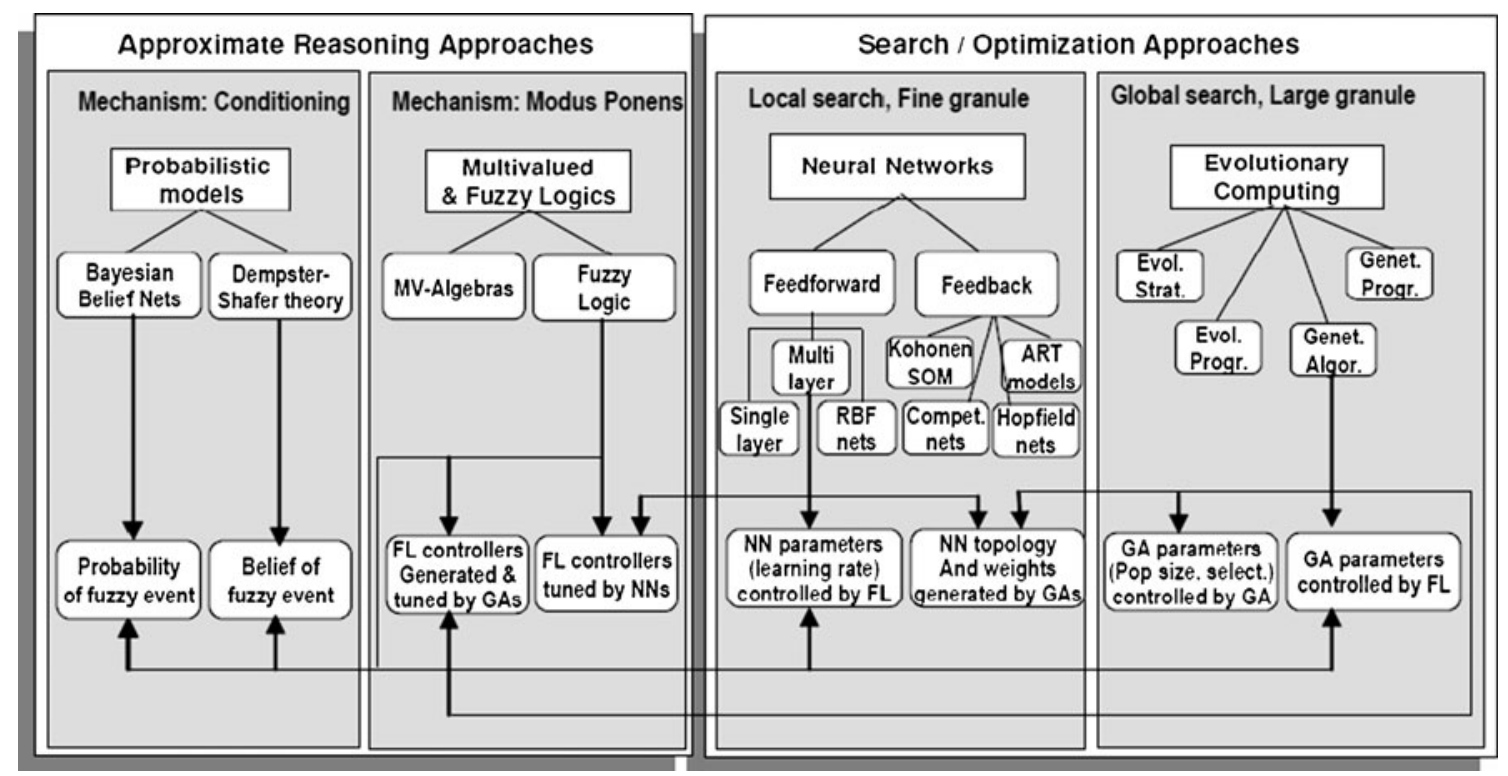

Fig. 2 A taxonomy of hybrid algorithms and their components for aspects of soft computing 
we can affect it, working with far less data, and less precise data, than would be required in order to use traditional, purely quantitative methods. Consider, for instance, the reasoning process when driving a car; and

- Scientists and engineers appear to use qualitative reasoning including:

- For initial understanding of a problem,

- When setting up more formal methods to solve particular problems,

- When interpreting the results of quantitative simulations, calculations, or measurements,

- To benefit from the representations and techniques that enable them to reason about the behavior of physical systems, without precise quantitative information needed by conventional analysis techniques such as numerical simulators, To model cases where causality is explicitly represented and used to explain the structure and behavior resulting from interactions among components of a system.

Below we discuss few application examples of soft computing in communities of active senior professionals.

(i) Quantitative analysis of factors in active ageing environments:
In the discipline of system dynamics (Ge et al. 2004) it is assumed that a complex system can be broken into smaller measurable elements (criteria). The criteria can then be analyzed using the causal modeling approach to study their causal behavior. The results of causal analysis can be represented in a diagram showing the relations among the criteria. These causal relations can also be translated into mathematical equations. The mathematical equations can be applied to make a formal analysis of the entire system. Figure 3 shows the application of the causal modeling approach to the system dynamics discipline; namely, first the generation of System dynamics based on causal models, followed by the definition of mathematical equations that lead the way to the design of the system architecture (Greenland and Brumback 2002).

In principle, these concepts could be applied to analyze different measurable factors that causally influence the activeness of retired people. The analysis results, once translated into mathematical equations, can be a base for making formal analysis of factors that causally influence the elder's activeness. The translated equations can also support the automation of some processes related to the analysis of factors influencing elder activeness. One practical example application of

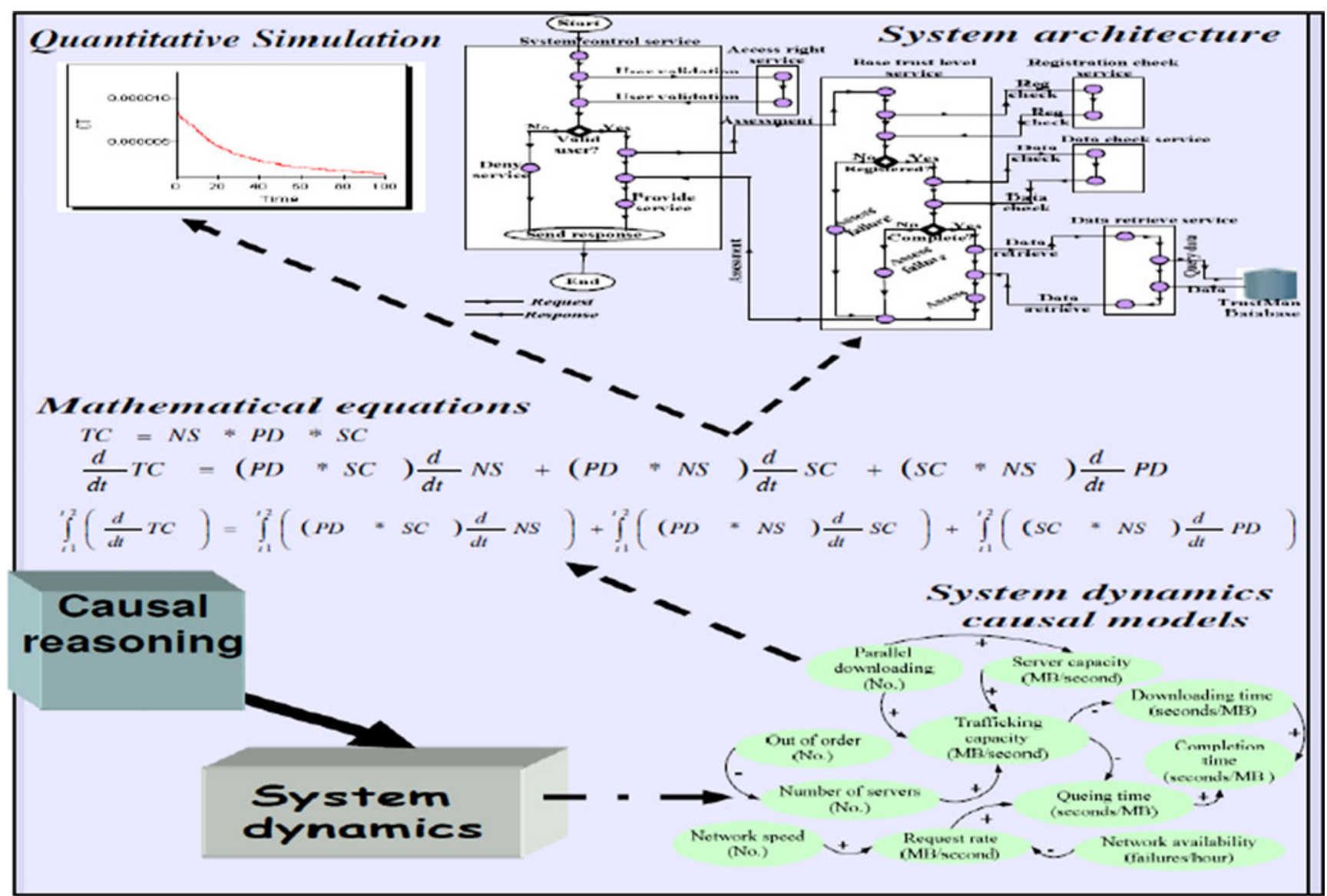

Fig. 3 The concept of causal analysis as applied in system dynamics and QR disciplines 
quantitative causal reasoning could be the analysis of the impact of changing the taxation rules for activities involving retired people.

\section{(ii) Qualitative analysis of factors in ePAL environments}

In the discipline of qualitative reasoning $(\mathrm{QR})$ it is assumed that some complex systems are characterized with parameters which are difficult to quantify or their measurable data are hard to collect. However, such systems can be analyzed through developing their QR based models that can be used to identify some values for these parameters with some qualitative degrees (e.g. large, medium, small, etc.). Furthermore, based on these qualitative values, the models can be simulated to analyze the causal influences among these qualitative parameters which represent the high level behavior of the entire system. The results of the causal analysis can then be applied to qualitatively examine the entire system (Greenland and Brumback 2002).

Qualitative analysis has been popularly applied in study of populations of living things. It has been for example applied to study population changes of particular species of plants in ecological studies. The ecological knowledge gained from a particular study is usually characterized as incomplete, fuzzy, uncertain, sparse, empirical, nonformalized, etc., and it is often expressed in qualitative terms, verbally or diagrammatically (Salles \& Bredeweg). Qualitative reasoning is an area of artificial intelligence that creates representations for continuous aspects of the world to support reasoning with little information. Particularly relevant for the study addressing imprecise situations is the support for analysis of qualitative parameters addressing their explicit representation of causal relationships between values of parameters. There are a number of aspects regarding activeness of retired professionals that can hardly be quantitatively characterized and measured. In the ePAL context, for instance, decisions made by retired professionals regarding joining some economical activities are causally influenced by many factors (e.g. possible benefits, motivation, impact to their health, impact to their social contacts, etc.) that cannot easily be studied with traditional mathematical approaches.

\subsection{Relevance of soft computing to ePAL environment}

Soft Computing introduces complex methodologies, applying methods and techniques from neural networks, genetic algorithms, fuzzy logic, Bayesian networks, and their hybrids, in order to support approximate reasoning, with imprecision, uncertainty, and partial truth. Namely, it mimics the remarkable human capability of making decisions in real-life, within ambiguous environments.

ePAL environment, as stated earlier, forms a community, constituting senior professionals who need to interact and collaborate similar to younger generations, despite their old age. But since they are not regular workers and more vulnerable, more vagueness, impreciseness, and incompleteness is expected to be experienced in the ePAL environment. Approaches and systems supporting senior professionals to make decision in such environments are needed, for which soft computing represents a potential domain of research to develop the required solutions.

7.3 Further required research on soft computingapplicable to ePAL environments

A key challenge related to soft computing research lies in judicious integration of the merits of its component technologies so that the resulting one has applicationspecific advantages, which cannot be achieved using the individual techniques alone, in decision making. Although the soft computing as well as qualitative reasoning fields has addressed diverse problem areas and developed a variety of theories and systems, there are a number of prominent features that are typical for many of the approaches. Some of the most important ones are as follows:

\section{(i) Development of ontologies for various concepts in CASPs collaborative environments}

There is a need for providing an explicit representation of the conceptual modeling layer for example as addressed in studies in the qualitative reasoning field. This layer is crucial to any attempt to support model building and even more to automate it and has been one of the major issues of the field. Particularly, for its application in collaborative environments further research needs to be done to enrich ontology specification which will support studies related to soft computing.

\section{(ii) Development of approaches to support or enhance analysis of causality for CASP related variables}

Analyzing and explaining the behavior of a system and its constituent variables in terms of cause-effect relations is central to human intuitive reasoning and communication but it is challenging to formally formulate mathematical expressions describing system behavior. Formalizing this concept and exploiting it in automated reasoning is the basis for explanation facilities in model-based systems which is still in need for further research.

\section{(iii) Development of an approach and a framework for compositional modeling of CASP elements}

Most qualitative reasoning systems adopt a reductionist view of the world and aim at building libraries of elementary, independent model fragments (component behavior, processes, and so on). This approach provides 
the basis for automating the model composition and reusing models, a highly desirable feature for industrial applications. However, for this process to be performed effectively, a well-founded approach or framework must be developed which also is in need for further research.

\section{(iv) Addressing the qualitativeness of systems supporting operations in CASPS}

Qualitativeness means including only those distinctions in a behavior model that are essential for solving a particular task for a certain system. The goal is to obtain a finite representation that leads to coarse, intuitive representations of models and behavior (for example, as finite relations and a state graph, respectively), and efficient algorithms.

\section{Machine learning}

Many machine learning techniques are already available being the main challenges here the integration with the other components of a virtual community support system and the collection of adequate (historic) training data sets. Machine Learning is the science of building hardware or software that can achieve tasks by learning from examples (Katrenko and Adriaans 2006). The examples often come as \{input, output\} pairs. Given new inputs a trained machine can make predictions of the unknown output. Examples of machine learning tasks include: automatic reading of handwriting, assisted medical diagnosis, automatic text classification (classification of web pages; spam filtering), and stock exchange predictions.

For the ePAL context, examples of potential use of machine learning and data mining techniques include:

- Discovery of seniors' patterns of behavior within communities provided that historic data is collected regarding the participation of members in the community activities.

- Identifying the "emotional health" status of a collaborative network of senior professionals, through monitoring selected indicators.

- Optimization of collaboration processes based on historic data related to past performance.

In relation to the application of machine learning in ePAL environment as exemplified above, a number of research topics need to be addressed as further discussed in Sections 8.1, 8.2 and 8.3.

\subsection{Base concepts of machine learning}

Machine learning is a classical sub-field of Artificial Intelligence that is devoted to the design and develop- ment of algorithms and techniques that let computer systems improve automatically through experience (Alpaydın 2004). In other words, it aims to give computers the ability to "learn". The purpose of machine learning algorithms is to use observations (experiences, data, patterns) to improve a performance element, which determines how an agent or system reacts when it is given particular inputs (Bishop 2006). The performance element may be a simple classifier trying to classify an input instance into a set of categories or it may be a complete agent acting in an unknown environment. By receiving feedback on the performance, the learning algorithm adapts the performance element to enhance its capabilities (Mitchell 1997).

Applications range from discovering general rules in large data sets, to information filtering systems that automatically learn users' interests (Bishop 2006). Therefore a large set of practical systems have been developed for cases such as object recognition and computer vision, speech and handwriting recognition, game playing and robot control, error diagnosis and recovery systems, detecting credit card fraud, stock market analysis, classifying DNA (Deoxyribonucleic acid) sequences, medical diagnosis, and many others. Although still a very active research field with many open challenges, a large variety of algorithms and techniques are already available. One typical classification of this variety of algorithms includes (Mitchell 1997):

- Supervised Learning - The learning algorithms receive inputs and the correct outputs, and searches for a function which approximates the unknown target function. Then it learns how to predict the output values of new examples (mostly through an inductive process). Under this group we have typically classification and regression algorithms. Well known cases are decision trees and neural networks.

- Unsupervised Learning - The learning agent receives only input data and uses an objective function (such as a distance function) to extract / identify clusters in the input data or particular features which are useful for describing the data. The learning algorithm needs to generalize from the input patterns to discover the output values. This class is represented by several clustering algorithms.

- Semi-supervised Learning - This combines both classified and unclassified examples to generate an appropriate classifier.

- Reinforcement Learning - The learning agent receives an input and an evaluation (reward) of the action selected by the agent, and the learning algorithm has to learn a policy which maps inputs to actions resulting in the best performance. 
One of the key research fields in the area of machine learning addresses the aspects of data mining. Data mining refers to a process of extracting knowledge or relevant information from large sets of data. The data can be, for instance, historic data bases, data sets resulting from experiments and monitoring systems, etc. Data mining approaches can be divided into two separate processes: knowledge discovery and prediction. The result of knowledge discovery is an explicit representation (e.g. rules, classification tree) that has a readable form and can be understood by a user (Alpaydin 2004). Forecasting, or predictive modeling provides predictions of future events and may be transparent and readable in some approaches (e.g., rule-based systems) and opaque in others such as neural networks through collaboration among senior professionals. Examples of application include: (1) Finding all CASP membership applicants who have poor performance history (Classification), (2) Identifying senior professionals with similar interests (Clustering), and (3) Finding activities which are frequently performed through collaboration among senior professionals (Association rules). One possible classification of data mining techniques is:

- Predictive techniques which includes: classification, regression, time series analysis, and prediction.

- Descriptive techniques which includes: clustering, summarization, association rules and sequence discovery.

In terms of approaches, data mining techniques can be seen as an application of machine learning algorithms. But some more traditional techniques coming from the statistical area can also be applied.

\subsection{Relevance of machine learning to ePAL environment}

A key application of machine learning to the actual life of people is related to providing support in understanding the environment in order to forecast events and make decisions, based on the experiences from the past. Machine learning techniques can support practitioners in collecting the needed data on actions taken daily, and based on these data a pattern can be constructed showing how things have been happening in the past and their possible occurrence in the future.

Machine learning algorithms have proven to be of great practical value in a variety of application domains. Senior professionals shall be helped with these techniques, being properly informed on how the community members have acted in the past, based on the collected data. Furthermore, experiences from the past can help the seniors in handling the emerging challenges, e.g. how to gain knowledge and learn to use new technologies. Similarly, the development of specific software systems for senior professionals can benefit from the experiences gathered in the past, using machine learning techniques.

8.3 Further required research on machine learningapplicable to ePAL environments

Further research on different topics related to machine learning must be done to facilitate the designing and development of algorithms that allow the related concepts to be applicable in networks involving individuals such communities of active senior professionals. Below we present a few representative topics that are in need for further research.

(i) Develop machine learning-oriented tools to support the establishment of environments that empower seniors to leave a legacy that capitalizes on their personal / professional experience and is usable and transferable to the society

Personal and professional experience of seniors' should be made available to be used by other society generations, namely the younger generations or to allow the other members of the senior community to benefit from it. This legacy can be used if mechanisms to promote intergenerational inheritance and collective legacy are developed. These mechanisms should use other instruments such as talents modeling and user-centered knowledge acquisition tools. A means to provide incentives to seniors and encouraging them to leave their legacy behind is by creating some reward mechanisms, based on learning their cumulative performance. These mechanisms should consider the importance of the models for knowledge assessment and intellectual property. Further research is needed to address the following:

- Development of tools supporting inheritance and sharing of user-generated knowledge assets,

- Design of new networking models for elderly communities' involvement with the socio-economic system,

- Develop tools that support learning achievement of senior professionals to facilitate the rewarding process.

(ii) Addressing the computational limits of machine learning for large variety and volume of data in CASPS

Communities of active senior professionals are open but controlled border networks and thus they might be characterized with large datasets which are constantly growing. There is still a lack of suitable approaches and tools in research and practice to support learning from 
large and heterogeneous datasets. Currently, there are plenty of methods known for speeding up slow learning algorithms. However, speeding up fast learning algorithms operating online or in networked environment is a much more challenging problem. Another problem is related to the computational cost resulted from test time, because learned predictors should be deployable in realtime systems. Therefore, a related research challenge in need for further study is finding solution related to building effective learning algorithms that are operative in CASPs with very low computational cost required for test time.

\section{(iii) Development of reduction methods addressing mod- el complexity for data related to SPS}

Considering the complexity of the CASPs as collaborative networks, it is challenging to collect all data related to senior professionals which are needed to assess their required experience for machine learning purposes. The data in collaborative environment is very dynamic and can consist of very large variety and volume. The classification and labeling/modeling of the variables representing the data is quite challenging. In many situations there are only small amounts of labeled data considered, because labeling is costly and/or because the prediction task to solve them is very specific. In relation to labeling, two open questions that need further research refer to: (1) What are the limits of multitask learning and active learning? (2) How to reuse knowledge bases \& ontologies representing concepts of senior professionals and CASPs in machine learning?

\section{(iv) Addressing the problem of analyzing non-stationary data related to SPS}

The standard assumption in machine learning is that data sources do not change, but the data and their related sources in communities of active senior professionals are very dynamic. Thus some learning algorithms and tools need to be tuned to deal with changing both data and data sources in CASPs. This is an open challenge in need of further research.

\section{(v) Addressing the difficulties in learning to rank various solution for emerging opportunities in CASPS}

Typically there exists a large set of solutions from which an optimal one will need to be selected, for instance for decision-making in CASPS, in relation to formation of TSPs. As a step towards the needed selection, it requires to establish ranking mechanisms for all solutions based on certain set of indicators. A key challenge in need of further research is related to establishing the ranking policies and identifying the suitable indicators for various types of solutions.

\section{Towards realizing the research challenges}

The complexities of challenges among the addressed areas clearly differ in terms of the need for the intensity and duration of research and development. As such these challenges might be classified according to their needs for research and development, ranging from short-term to longterm. The main cause of this variation of needed time/ intensity is the current level by which the respective challenge has or has not been addressed through the past and on-going research. Following table summarizes our views on the nature of the required remaining research to realize the challenges in each of the four mentioned technical areas (Table 1).

Therefore, the presented research challenges aim at identifying needed enhancements to the current research and development achievements in the four related areas, in order to meet the demands and requirements for realization of the technological perspective of the ePAL environment; thus for establishing communities of active senior professionals.

\section{Conclusion}

In our work we have analyzed a number of research aspects related to technological perspective of active ageing of senior professionals. For each research aspect we have clarified its relevance to active ageing, identified research challenges that need further work and proposed some future work. We have also analyzed for each research aspect the currently achieved results in research as well as existing experience from practices that together contributes to the new challenges. While a large number of technological aspects are related to the full support of the ePAL environment, as described in Section 2 this paper has presented four main representative topics related to the technological perspective of ePAL communities, while only briefly addressing the others. For each presented topic namely, those of collaborative network (in Section 5), affective computing (in Section 6), soft computing (in Section 7), and machine learning (in Section 8), a number of specific challenges that are in need for further research are introduced and discussed. The paper therefore provides a high level research plan for the technological perspective of the ePAL, to support the senior professionals remain partially active after retirement. Validation of this research plan was obtained empirically as a part of the roadmapping process. This is achieved through the consolidation meetings and surveys performed with different ePAL stakeholders, and including a large number of experts in the field. 
Table 1 Main needed research

\begin{tabular}{|c|c|}
\hline Area of research & Achieved research results \\
\hline $\begin{array}{l}\text { Collaborative } \\
\text { networks }\end{array}$ & $\begin{array}{l}\text { During the last years a number of research projects have } \\
\text { addressed different aspects of collaborative networks. A } \\
\text { large volume of innovative solutions are addressed in } \\
\text { proceedings of the PRO-VE conferences 1999-2010. } \\
\text { Some areas that have been extensively addressed include } \\
\text { formalization and modeling of CN concepts (e.g. ARCON } \\
\text { framework (Camarinha-Matos and Afsarmanesh 2008a, } \\
\text { b)), configuration of temporary consortiums (e.g. WiZan } \\
\text { (Oliveira and Camarinha-Matos 2008)), analysis of rational } \\
\text { trust in organizations (TrustMan, (Afsarmanesh et al. } \\
\text { 2008)), Ontology specification (ODMS, (Afsarmanesh et } \\
\text { al. 2008)). Etc. }\end{array}$ \\
\hline
\end{tabular}

Affective computing

The topic of affective computing is a new area of research and development, which has many unresolved challenges related to capturing and processing emotions of senior professionals in their collaborating associations.

Particularly in relation to human computer interaction, this area of research needs innovation to design context aware user interfaces.

Soft computing

Developing many $\mathrm{CN}$-related support tools rooted in the areas of soft computing is also new and in need of formal in-depth specification, modeling and development of innovative support tools. Some aspects characterized with soft issues in collaborative environments have already benefited from initial models developed with soft computing approaches in mind. An example of application area is the analysis of trust in organizations based on the causal analysis of trust criteria (Msanjila and Afsarmanesh 2008). However, to properly benefit from the application of promising approaches of soft computing, further research needs to be done related to modeling advanced aspects and developing functionalities.

Machine learning
Dealing with individual professionals, and supporting their co-working and collaboration, outside their traditional hierarchic work environment, creates many complexities which need to be properly modeled. Application of several machine learning approaches to this problem domain has so far produced some promising results. However, these approaches are not yet applied and tested in real $\mathrm{CN}$ environments in order to improve the new solutions or to improve the processing aspects of the tools developed for CASPs.
Foreseen required research

Solving some challenges for the ePAL context as presented in Sections 5.2 and 5.3 of this paper, research in the area of collaborative networks might require customization or application of some existing solutions to the associations of senior professionals, while some others such as challenge (ii) in Section 5.3, requires R\&D on requirement analysis and development of corresponding support functionalities.

Thus there are some aspects that might need short-term research projects to be thoroughly addressed such as those in need for customization of the existing solutions.

However, other challenges that might need development of solution concepts and tools require medium or long term research.

This area still lacks suitable solutions that can be either customized or applied to solving the identified challenges in this document. In order to apply the concepts of affective computing in CASP environments as well as the configured TSP, research projects must address the development of formal models and tools that address the promotion of senior involvements and their contentment, in relation to all challenges from (i) to (viii) in Section 6.3. Therefore, mostly long-term research is required to address these specificities.

Soft computing approaches have so far been applied in CNrelated areas mostly for their qualitative modeling and subject analysis, such as analysis of trust in which the opinion-based approach has been applied. In emerging collaborative networks such as CASPs and TSPs however, the analysis trends are moving further towards rational and formal approaches. Subjective views can hardly provide suitable solutions for challenges such as (ii) and (iii) in Section 7.3. While some research in this area has already started, more medium term to long term research is needed to address the application of soft computing in rational and formal analysis of certain aspects such as trust and collaboration readiness, to support the development of required tools and functionalities to support networks of senior professionals.

Besides developing new concepts, models and tools for $\mathrm{CN}$ environments, to support a complex aspect such as how to leave the seniors' legacy for next generation, it is extremely important that the validity of the new approaches and models are put to test. Furthermore, depending on the test results, it is important to learn and improve the designed model, e.g. through changing the weights for different parameters. This approach however requires collecting data from real usage in $\mathrm{CN}$ environments. While some of the mentioned challenges are general to applying machine learning approach, long-term in-depth research is required to develop new solutions for CN-related challenges such as those stated in (i) and (v) in Section 8.3.
Although there are a large number of challenges related to various research disciplines that need to be addressed to smoothen the establishment and operation of networks of senior professionals, those related to the technologies and applications are amenably more in number and strongly in need for extensive innovation. A number of foreseen challenges that needed future medium or long term research for the aspects addressed in this paper are summarized in Table format within Section 9. 
Acknowledgements This work was funded in part by the European Commission through the ePAL project.

Open Access This article is distributed under the terms of the Creative Commons Attribution Noncommercial License which permits any noncommercial use, distribution, and reproduction in any medium, provided the original author(s) and source are credited.

\section{References}

Abraham, A., Das, S., \& Roy, S. (2007). In O. Maimon \& L. Rokach (Eds.), Swarm intelligence algorithms for data clustering, soft computing for knowledge discovery and data mining (pp. 279313). Germany: Springer Verlag. ISBN 978-0-387-69934-9.

Afsarmanesh, H. \& Camarinha-Matos, L. M. (2005). A framework for management of virtual organizations breeding environments. In Proceedings of 6th PRO-VE'05 - Collaborative Networks and their Breeding Environments, (pp. 35-48), Valencia, Spain: Springer, 26-28.

Afsarmanesh, H. \& Camarinha-Matos, L. M. (2009). On the classification and management of virtual organization breeding environments. In the International Journal of Information Technology and Management - IJITM, Inderscience publisher. 8(1), 1741-5179.

Afsarmanesh, H. \& Msanjila, S. S. (2010). ePAL Vision 2020 for active ageing of senior professionals. In Proceedings of PRO-VE 2010 conference. Saint-Etienne, France, October.

Afsarmanesh, H., Msanjila, S. S., Ermilova, E., Wiesner, S., Woefel. W., \& Seifert, M. (2008). VBE management system. In Methods and tools for collaborative networked organizations. ISBN: 9780-387-79423-5, (pp. 119-154), Springer: New York.

Afsarmanesh, H., Camarinha-Matos, L. M., \& Msanjila, S. (2009). A well-conceived vision for extending professional life of seniors. In proceedings of PRO-VE 2009 conference. Thessalonica, Greece: Springer.

Aggarwal, J. K. \& Cai, Q. (1999). Human motion analysis: a review. Computer Vision and Image Understanding, 73(3).

Aguilar, J. M., Cantos, J., Exposito, G., \& Gómez, P. (2004). The improvement of the quality of life for elderly and relatives through two tele-assistance services: The TeleCARE approach. In Proceedings of TELECARE 2004 Workshop - Tele-Care and Collaborative Virtual Communities (pp. 73-85). INSTICC: Porto, Portugal.

Alpaydın, E. (2004). Introduction to machine learning (Adaptive Computation and Machine Learning), MIT Press, ISBN 0262012111.

Avramov, D. \& Maskova, M. (2003). Active ageing in Europe. Population Series No. 41, ISBN 978-92-871-5240-4.

Bishop, C. M. (2006). Pattern recognition and machine learning. Springer ISBN 0-387-31073-8.

Camarinha-Matos, L. M. \& Afsarmanesh, H. (2004). A roadmapping methodology for strategic research on VO. In Collaborative Networked Organizations-A research agenda for emerging business models, cap. 7.1, Springer: Boston.

Camarinha-Matos, L. M. \& Afsarmanesh, H. (2006). Collaborative networks: Value creation in a knowledge society, (invited keynote paper). In Proceedings of PROLAMAT 2006, IFIP Int. Conf. On Knowledge Enterprise-New Challenges. Springer: Shanghai, China.

Camarinha-Matos, L. M., \& Afsarmanesh, H. (2008a). Methods and Tools for Collaborative Networked Organizations. New York: Springer. ISBN 978-0-387-79423-5.

Camarinha-Matos, L. M. \& Afsarmanesh, H. (2008b). Classes of collaborative networks. In the Encyclopedia of Networked and Virtual Organizations. In G. Putnik \& M. M. Cunha (Eds.), Idea Group.
Camarinha-Matos, L. M. \& Afsarmanesh, H. (2009). The need for a strategic R\&D roadmap for active ageing. In Leveraging knowledge for innovation in Collaborative Networks (pp. 669680) Springer.

Camarinha-Matos, L. M., Afsarmanesh, H., del Cura, A., \& Playfoot, J. (2010). ePAL Roadmap for Active Ageing - A Collaborative Networks Approach to Extending Professional Life. In Proceedings of AGEmap Workshop / Pervasive Health 2010 conference, Munich, Germany.

Canziani, P. \& Petrongolo, B. (2001). Firing costs and stigma: A theoretical analysis and evidence from microdata. In European Economic Review, 45(10), 1877-1906.

Carey, D. (2009). Ageing populations: How the Dutch cope. In Organization for economic co-operation \& development. http://www.oecdobserver.org/news/fullstory.php/aid/741/ Ageing_populations:_How_the_Dutch_cope.html.

Cramer, H. S. M. (2007). Interaction with user-adaptive information filters. Trust, transparency and acceptance. CHI '07 extended abstracts, San Jose, Ca, USA, pp. 1633-1636.

Crave, S., Bouron, T., \& Ladame, S. (2006). Using social capital as a conceptual framework for professional virtual communities formalization. In IFIP International Federation for Information Processing, vol. 224, Network-Centric collaboration and supporting framework, pp. 317-378.

del Cura, A.; Camarinha-Matos, L. M., \& Ferrada, F. (2009). New organizational forms to extend the professional active life. Proceedings of PRO-VE'09, 7-9 Oct 09, Thessaloniki, Greece, Leveraging knowledge for innovation in Collaborative Networks (pp. 721-732) Springer.

Eyster, L., Johnson, R. W., \& Toder, E. (2008). Current strategies to employ and retain older workers [Final report to the Department of Labor]. Washington, DC: The Urban Institute. Retrieved from http://www.urban.org/publications/411626.html.

Fredrickson, B. L. (2003). The value of positive emotions. American Scientist, 91, 330-335.

Ge, Y., Yang, J. B., Proudlove, N., \& Spring, M. (2004). System dynamics modeling for supply-chain management: A case study on a supermarket chain in the UK. In the International Transactions in Operational Research, 11, 495-509.

Greenland S. \& Brumback, B. (2002). An overview of relations among causal modeling methods. In International Journal of Epidemiology. ISBN: 31-1030-1037.

Hernandez-Encuentra, E., Pousada, M., \& Gomez-Zuniga B. (2009). ICT and older people: Beyond usability. In Educational Gerontology, Special issue on Adult Education and Lifelong Learning. $35(3), 226-245$.

HSBC Insurance. (2007). The future of retirement-The new old age. May 2007. Retrieved from www.hsbc.com/1/PA_1_1_S5/content/ assets/retirement/gender_perspective_eurasia_africa_1.pdf.

IPWEA. (2006). Guide to Retaining the Current Workforce. IPWEA National Skills Shortage Project, Institute of Public Works Engineering Australia. Jul 2006. www.ipwea.org.au/skills/upload/ NSSP1_Retaining_Current_Workforce.pdf.

Jettinghoff, K. \& Houtman I. (2007). People more willing to work until retirement age. In European Working Conditions Observatory, (http://www.eurofound.europa.eu/ewco/2007/ 04/NL0704079I.htm).

Karuppiah, D., Degaan, P., Araujo, E., Yang, Y., Holnes, G., Zhu, Z., et al. (2001). Software mode changes for continuous motion tracking. In self adaptive software, ISBN 3-540-41655-2, pp. 161-180.

Katrenko, S. \& Adriaans, P. (2006). Learning relations from biomedical corpora using dependency trees. Invited paper in KDECB (Knowledge Discovery and Emergent Complexity in BioInformatics), Lecture Notes in Bioinformatics. LNBI, vol. 4366.

Laddaga, R., Robertson, P., \& Shrobe, H. (2003). Introduction to selfadaptive software: Applications. In Self-Adaptive Software: 
Applications, Lecture Notes in Computer Science, ISBN 978-3540-00731-9, LNCS 2614, pp. 275-283.

Lee, C.M., Narayanan, S., \& Pieraccini, R. (2001). Recognition of negative emotion in the human speech signals, workshop on auto. Speech Recognition and Understanding.

Leonard, W., Afsarmanesh, H., Msanjila, S. S., \& Playfoot, J. (2009). Exploring the gap for effective extension of professional life in Europe. $\mathrm{n}$ the proceedings of 10th IFIP Working Conference on virtual enterprises (PRO-VE 2009), Thessalonike, Greece.

Lundberg, S. (2007). Elite care brings elder friendly technology to Oregon. In the bimonthly newspaper of the American society on ageing-special issue on ageing today. xxviii(5), ISBN 1043 1284, September.

Minehan, M. (1997). The aging baby boomers - impact of postretirement employment on companies HR Magazine, (www. hrmagazine.co.uk/).

Mitchell, T. (1997). Machine Learning, McGraw Hill. ISBN 0-07042807-7.

Msanjila, S. S. \& Afsarmanesh, H. (2008). A multi-model approach to analyze inter-organizational trust. In Collaborative Networks reference modeling. ISBN: 978-0-387-79425-9, (pp 195-216). New York: Springer.

Msanjila, S. S. \& Afsarmanesh, H. (2009). On hard and soft models to analyze trust life cycle for mediating collaboration. In proceedings of PRO-VE 2009 conference. Thessalonica, Greece: Springer.

Oliveira, A. I. \& Camarinha-Matos, L. M. (2008). Agreement negotiation wizard. In Methods and Tools for Collaborative Networked Organizations, ISBN: 978-0-387-79423-5, (pp. 191218). New York: Springer.

Osterweil, L. J. \& Clarke, L. A. (2001). Continuous self evaluation for the self-improvement of software. In self adaptive software, ISBN 3-540-41655-2, pp 27-39.

Picard, R. W. (1995). Affective computing. MIT Technical Report \#321.

Picard, W. (2006). Adaptive collaboration professional virtual communities via negotiation of social protocols. In IFIP International Federation for Information Processing, vol. 224, Network-Centric collaboration and supporting framework, pp. 353-360.

Salles, P., \& Bredeweg, B. (2006). Modelling population and community dynamics with qualitative reasoning. Ecological Modelling, 195(1-2), 114-128.

Tao, J. \& Tieniu, T. (2005). Affective computing: A review. Affective Computing and Intelligent Interaction. LNCS 3784. Springer. pp. 981-995.

Turbe-Suetens, N. \& Kouloumdjian, M. -F. (2009). Active ageing workforce in virtual environment - methodology and innovationeSangathan White Paper, http://www.scribd.com/doc/6121465/ Active-Ageing-Workforce-in-Virtual-Environment-Methodologyand-Innovation-eSangathan-White-Paper.

Vontas, A., Protogeros, N., \& Moumtzi, V. (2009). Practices and services for enabling the independent living of elderly population. In Leveraging Knowledge for Innovation in Collaborative Networks, IFIP AICT 307, (pp. 753-758), Heidelberg: Springer.

Walker, D. (2007). Older workers: Some best practices and strategies for engaging and retaining older workers. Testimony before the U.S. Senate Special Committee on Aging, February 28, 2007.

WHO. (2002). "Active aging: A policy framework" WHO/NMH/ NPH/02.8, World Health Organisation report.

Hamideh Afsarmanesh has obtained her $\mathrm{PhD}$ in Computer Science from the University of Southern California (USC) in 1985. She is a full professor of Computer Science at the University of Amsterdam in the Netherlands, where she heads the FCN (Federated Collaborative Networks) group within the Informatics Institute. Her current research focuses on the areas of Federated /Distributed Cooperative Databases, Virtual Organizations /Virtual Laboratories /Virtual Communities, Integration of Autonomous and Heterogeneous Databases, and the design and development of web-based information systems for a variety of domains such as Biodiversity, Manufacturing, Teleassistance, and Distributed Control. She has directed research in more than twenty National, European, and International projects. She has been involved in the organization and has initiated / chaired several International conferences and workshops. She has published more than 150 articles in journals, books, and refereed conference proceedings in computer science research. She has co-edited more than twenty books and various issues of international Journals. She is a member of the editorial board of the journals of IJITM, IJASM, IJMLO, and IJEA. She is the chair of the general assembly for the SOCOLNET (Society of Collaborative Networks). She is the Dutch representative at the IFIP TC5, a member of the IFIP TC5-WG5.3, and the elected chair for the TC5- WG5.5 (COVE).

Simon Samwel Msanjila graduated BSc. Computer Science in 2001 from the University of Dar es Salaam, Tanzania; MSc. in Systems Engineering in 2004 from the Delft University of Technology, The Netherlands; and $\mathrm{PhD}$ in Computer Science in 2009 from the University of Amsterdam, The Netherlands. Currently, he is employed as a Senior Lecturer at the Mzumbe University in Morogoro, Tanzania. He is also the head of information and communication technology department. In addition to teaching a number of courses in Computer Science disciplines, he conducts research focusing on the establishment and management of collaborative networks of organizations. In the area of collaborative networks, Dr. Msanjila focuses on the management of information to support business operations conducted within these networks. Currently he is performing research on development of a collaborative ICT infrastructure supporting the provision of online - live and offline - HIV/AIDS advisory services to students and younger generation in Tanzania. Dr. Msanjila has published a more than 40 papers in journals, as book chapters, and in peer reviewed-book format international conference proceedings.

Luis M. Camarinha-Matos received his $\mathrm{PhD}$ degree in Computer Engineering from the New University of Lisbon, Portugal, in 1989 and a Doctor Honoris Causa degree by the Technical University of Bucharest, Romania, in 2009. He is currently full Professor and head of the Robotics and Integrated Manufacturing Group at the New University of Lisbon. $\mathrm{He}$ is also the leader of the Collaborative Networks and Distributed Industrial Systems (CoDIS) research group at the UNINOVA institute. He has participated in many international and national projects, both as a researcher and as a project scientific coordinator. His main areas of current research include: Collaborative networks (virtual enterprises / virtual organizations, virtual communities), multi-agent systems, intelligent manufacturing systems. He has been involved in the organization and program committees of many international conferences, has edited various issues of Journals and books, and he has more than 300 publications in Journals and conferences proceedings. He started the series of conferences BASYS (on balanced automation systems), PRO-VE (Infrastructures for Virtual Enterprises), and DoCEIS (Doctoral Conference on Computing, Electrical and Industrial Systems). He is the founder and former chair of the IFIP COVE working group WG5.5 on virtual enterprises and is founder and current president of the international Society of Collaborative Networks (SOCOLNET). 